\title{
PROCESSING, MICROSTRUCTURE, AND PROPERTIES OF MULTIPHASE Mo SILICIDE ALLOYS
}

C. T. LIU, J. H. SCHNEIBEL, and L. HEATHERLY
Metals and Ceramics Division, Oak Ridge National Laboratory, Oak Ridge, TN 3783 RfFAE/VED liuct@ornl.gov

\section{ABSTRACT}

Multiphase Mo silicide alloys containing $\mathrm{T} 2\left(\mathrm{Mo}_{5} \mathrm{SiB}_{2}\right), \mathrm{Mo}_{3} \mathrm{Si}$ and Mo phases were prepared by both melting \& casting (M\&C) and powder metallurgical (PM) processes. Glassy phases are observed in PM materials but not in M\&C materials. Microstructural studies indicate that the primary phase is Mo-rich solid solution in alloys containing $\leq(9.4 \mathrm{Si}+13.8 \mathrm{~B}$, at. \%) and $\mathrm{T} 2$ in alloys with $\geq(9.8 \mathrm{Si}+14.6 \mathrm{~B})$. An eutectic composition is estimated to be close to Mo-9.6Si-14.2B. The mechanical properties of multiphase silicide alloys were determined by hardness, tensile and bending tests at room temperature. The multiphase alloy MSB-18 (Mo-9.4Si-13.8B) possesses a flexure strength distinctly higher than that of $\mathrm{MoSi}_{2}$ and other $\mathrm{Mo}_{5} \mathrm{Si}_{3}$ silicide alloys containing no Mo particles. Also, MSB-18 is tougher than $\mathrm{MoSi}_{2}$ by a factor of 4 .

\section{INTRODUCTION}

Recently, the interest in Mo silicides for high-temperature structural applications has shifted from $\mathrm{MoSi}_{2}$-base to $\mathrm{Mo}_{5} \mathrm{Si}_{3}$-base compositions[1-6]. This is because $\mathrm{Mo}_{5} \mathrm{Si}_{3}$ contains more $\mathrm{Mo}$ and possesses a better creep resistance at elevated temperatures [2]. The silicide $\mathrm{Mo}_{5} \mathrm{Si}_{3}$, on the other hand, has much poor oxidation resistance at high temperatures. However, the oxidation properties of $\mathrm{Mo}_{5} \mathrm{Si}_{3}$ can be substantially improved by adding boron, as mentioned in the article of Nowotny et al. [7]. The excellent oxidation resistance of $\mathrm{Mo}_{5} \mathrm{Si}_{3}$-base silicides doped with $\mathrm{B}$ has been confirmed recently by Meyer et al. [1-3]. Berczik found that even small amounts of $\mathrm{B}$ and $\mathrm{Si}$ significantly improve the oxidation properties of Mo base alloys [8]. At present, considerable efforts have been devoted to the study of the Mo-Si-B system.

The phase diagram of the ternary system Mo-Si-B was first constructed by Nowotny et al. in 1957 [7], and has been further modified by Perepezko and his co-workers [4,5]. Figure 1 shows the Mo-rich section of the phase diagram reported by Perepezko et al. This phase section contains a number of intermetallic phases, including $\mathrm{Mo}_{3} \mathrm{Si}, \mathrm{Mo}_{5} \mathrm{Si}_{3}(\mathrm{~T} 1), \mathrm{Mo}_{5} \mathrm{SiB}_{2}$ (T2), $\mathrm{MoB}$, and $\mathrm{Mo}_{2} \mathrm{~B}$, which are all brittle at ambient temperatures. The existence of the stable ternary compound, $\mathrm{Mo}_{5} \mathrm{SiB}_{2}$, provides a number of ternary phase fields, as indicated in Fig. 1. Schneibel et al. [6] indicated that the silicide alloy Mo-26.7Si-7.3B (at. \%) located in the T1-T2-Mo $\mathrm{Mi}_{3}$ field was very brittle at room and $1200^{\circ} \mathrm{C}$. Among the three-phase regions, the T2- $\mathrm{Mo}_{3} \mathrm{Si}-\mathrm{Mo}$ field is of particular interest for possible structural use. This is because this field contains a relatively ductile Mo-rich solid solution, which is thermodynamically stable with the two silicide phases of $\mathrm{Mo}_{3} \mathrm{Si}$ and T2. In other words, it is possible to toughen the multiphase silicide phases by ductile Mo particles.

Perepezko et al. recently constructed the pseudo binary phase diagram of the Mo-T2 section [4,5]; nevertheless, no mechanical property data were reported. The objective of the current work is to understand the correlation among material processing, microstructural features, and mechanical properties of $\mathrm{T} 2-\mathrm{Mo}_{3} \mathrm{Si}-\mathrm{Mo}$ alloys. This understanding is expected to provide scientific guidance for the design of tough Mo silicide alloys.

\section{EXPERIMENTAL PROCEDURES}

MSB (Mo-Si-B)Alloys containing 8.5-10Si and 12.8-15.0B (at. \%) were processed by powder metallurgy $(\mathrm{PM})$ and melting and casting $(\mathrm{M} \& \mathrm{C})$. M\&C alloys were prepared by arc melting and drop casting into $\mathrm{Cu}$ molds, using high-purity charge materials. The alloy MSB-18 (Mo-9.4Si- 


\section{DISCLAIMER}

Portions of this document may be illegible in electronic image products. Images are produced from the best available original document. 

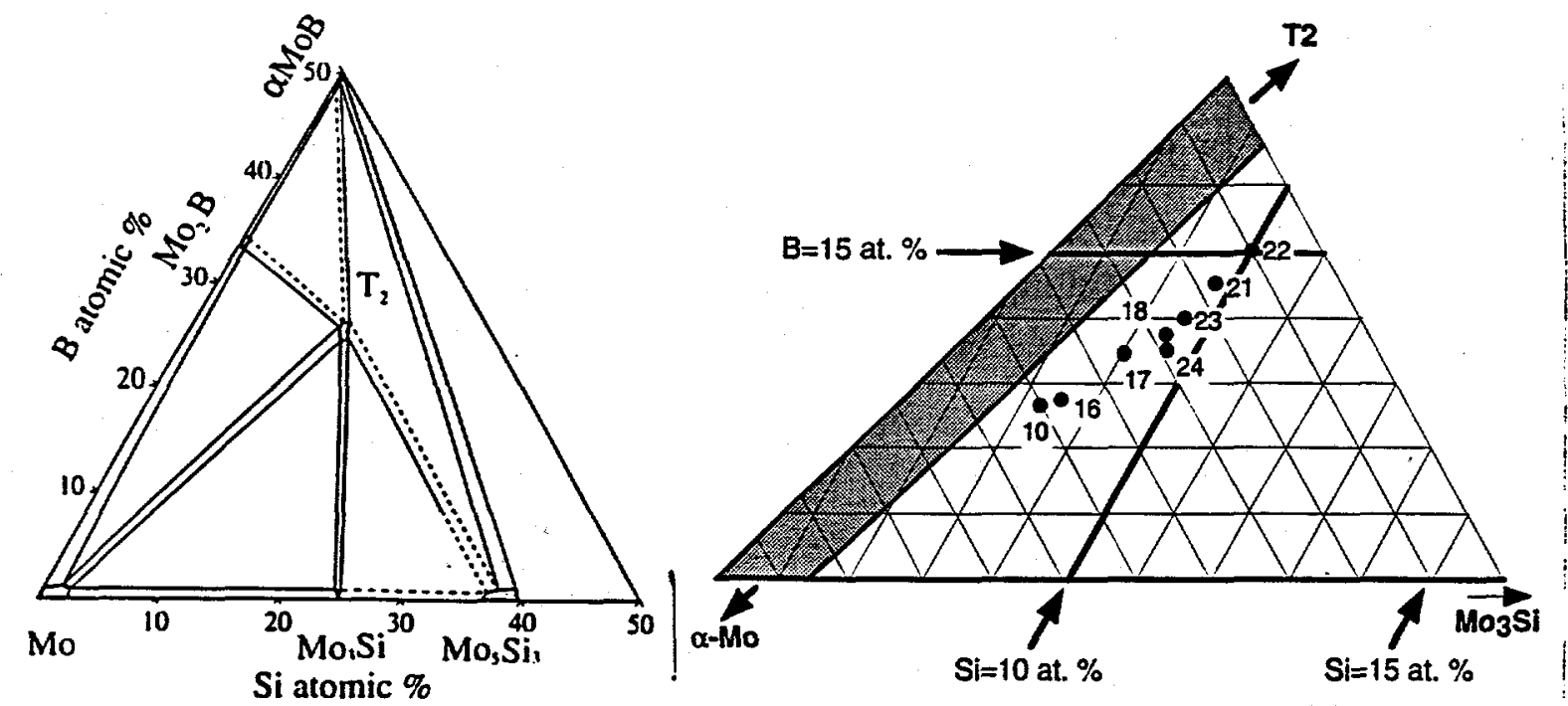

Fig. $1 \mathrm{Mo}-\mathrm{Mo}_{5} \mathrm{Si}_{3}-\mathrm{MoB}$ phase diagram [5] Fig. 2 Alloy compositions in the Mo-T2-Mo 3 Si field

13.8B) was also prepared by PM using elemental powders. The PM processing was carried out by mixing elemental powders in argon and hot-pressing compacts in vacuum in a 60-mm diameter graphite die at $1650^{\circ} \mathrm{C}$ and $48 \mathrm{MPa}$. All alloy ingots were homogenized at $1400^{\circ} \mathrm{C}$ for $150 \mathrm{~h}$ in vacuum. Metallographic samples in as-cast and homogenized conditions were etched and examined by optical microscopy. The phase composition of unetched samples was determined by electron microprobe analyses. Alloy specimens of MSB-18 prepared by M\&C were ground into powder, which was then screened to a size of $<45 \mu \mathrm{m}$. Powder $\mathrm{x}$-ray diffraction patterns were obtained using $\mathrm{Cu} \mathrm{K}_{\alpha}$ radiation. Flexure bars with cross sections of $3 \times 4 \mathrm{~mm}$ were electrodischarge machined, ground, and tested in air by 3 point bending with a span of $20 \mathrm{~mm}$ and a cross-head speed of $10 \mu \mathrm{m} / \mathrm{s}$. Microhardness measurements were conducted using 500 and $20 \mathrm{~g}$ loads. The lower load was used to measure the hardness of individual phases and the larger load was for measuring the average hardness of multiphase alloys. Tensile tests with ground buttonhead specimens were performed at room temperature at a cross head speed of $3.3 \times 10^{-3} / \mathrm{s}$.

\section{RESULTS}

Figure 2 shows the compositions of MSB alloys, which are located away from the Mo-T2 twophase region and within the $\mathrm{T} 2-\mathrm{Mo}_{3} \mathrm{Si}-\mathrm{Mo}$ field. The oxygen and carbon contents were determined by wet chemistry. M\&C materials typically contain about 300 wppm oxygen and 200 wppm carbon, whereas PM MSB-18 has 1100 wppm oxygen and 600 wppm carbon. Metallographic examination indicates no formation of glassy phases in $\mathrm{M} \& \mathrm{C}$ materials but borosilicate and $\mathrm{SiO}_{2}$ glasses in PM MSB-18.

The optical microstructures of M\&C MSB-10 (Mo-8.2Si-12.7B, at. \%) in the as-cast and homogenized conditions are shown in Fig. 3, where primary Mo patches (bright contrast) are surrounded by the multiphase matrix with an eutectic appearance. The $1400^{\circ} \mathrm{C}$ homogenization resulted in coarsening the matrix structure but not affecting Mo patches. The microhardness of the as-cast sample is 3.13 and $1280 \mathrm{DPH}$, respectively for Mo patches and the matrix phase, with an average hardness of $898 \mathrm{DPH}$ for the alloy. The homogenization moderately lowers the hardness: 220,1060 , and 819 for the corresponding phases and alloy. Metallographic examination shows no micro- and macro-cracks but some casting porosity, with an average porosity size of $\sim 12 \mu \mathrm{m}$ in $\mathrm{M} \& \mathrm{C}$ alloys. 

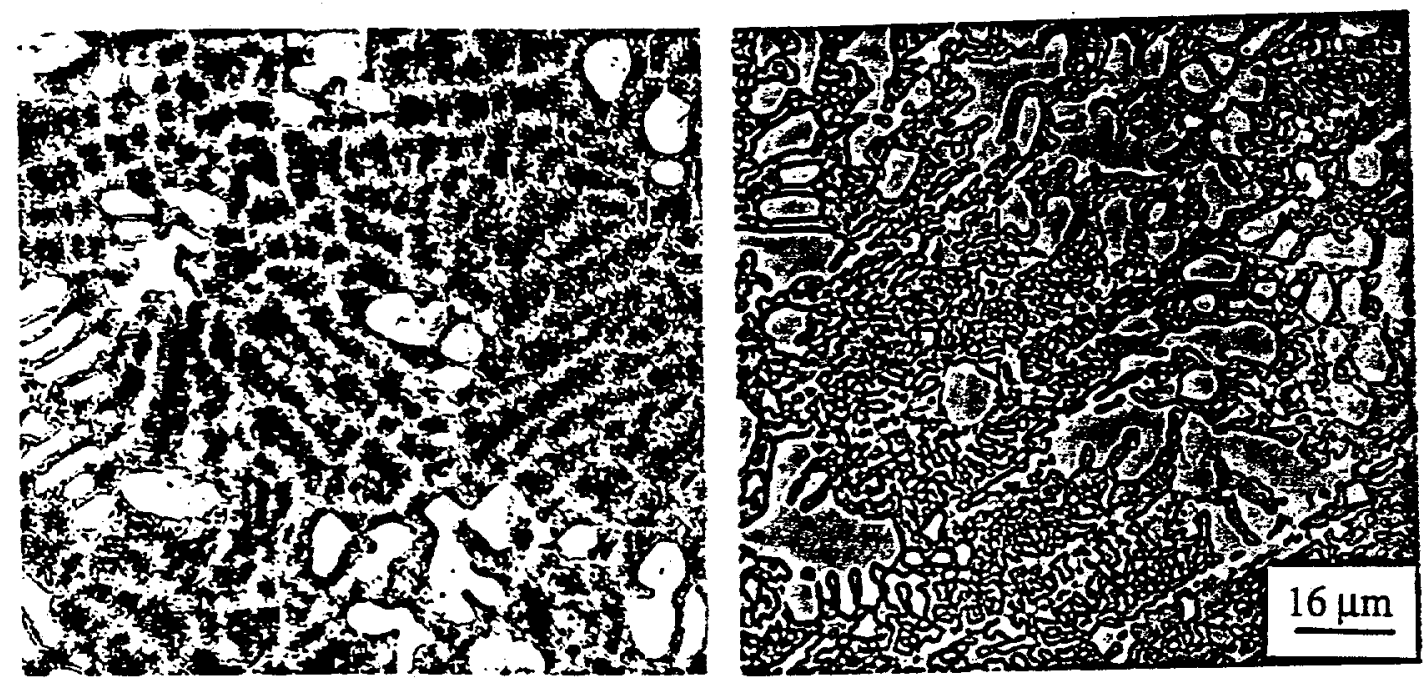

Fig. 3 Microstructures of (a) as-cast and (b) homogenized MSB-10 (Mo-8.2Si-12.7B)

Figure 4 compares the back-scattered images of M\&C MSB-18 (Mo-9.4Si-13.8B) and -21 (Mo9.8Si-14.6B) in the homogenized condition. Electron microprobe analyses of MSB-18 indicate that the primary Mo-rich phase (bright contrast) contains $2.5 \mathrm{Si}$ and $1.3 \mathrm{~B}$ (at. \%), and that the matrix is composed of three phases: Mo-rich solid solution, $\mathrm{Mo}_{3} \mathrm{Si}$ (gray contrast, Mo-21.6 Si-8.3B), and T2 (dark contrast, Mo-10.5Si-35.7B). The corresponding powder pattern of MSB-18 is shown in Fig. 5. In consistence with the microprobe analyses, all diffraction peaks in Fig. 5 can be identified from the standard diffraction patterns of the Mo, T2, and $\mathrm{Mo}_{3} \mathrm{Si}$ phases. In contrast to MSB-18, the primary phase formed in MSB-21 (see Fig. 4b) is T2 (dark contract, Mo-10.6Si-35.7B), instead of the Mo-rich phase. Since only few primary T2 particles are detected, the composition of MSB-21 should be close to the matrix composition.

The microstructure of PM MSB-18 is shown in Fig. 6, which is quite different from that of M\&C material (Fig. 4a). The PM material shows a regular mixture of three phases (Mo-rich, $\mathrm{Mo}_{3} \mathrm{Si}$, and T2), with no indication of formation of any eutectic structures. Note that the composition of the three phases in the PM material is comparable to that in $\mathrm{M} \& \mathrm{C}$ material, indicating that the PM material was equilibrated during processing and homogenization. Electron microprobe analyses reveal that black dots observed in the PM material are glassy phases, with borosilicate compositions mainly for smaller dots and $\mathrm{SiO}_{2}$ for larger dots. Note that no glassy phases were detected in M\&C materials. The hardness of the PM material (1160 DPH for the silicide phases and 820 for the alloy ) is comparable to that of M\&C materials.

The mechanical properties of PM and M\&C MSB-18 were determined by tensile and bending tests. Both materials showed no macroscopic plastic deformation in tension at room temperature, with the fracture strength of 345 and $358 \mathrm{MPa}$ for $\mathrm{M} \& \mathrm{C}$ and $\mathrm{PM}$ materials, respectively. Table 1 summarizes the results for the PM material obtained from flexure tests at room temperature. The fracture toughness increases from $7.9 \mathrm{MPa} \mathrm{m}^{1 / 2}$ for the as-pressed material to $10 \mathrm{MPa} \mathrm{m}^{1 / 2}$ for the homogenized one. The flexure strength is measured to be $570 \mathrm{MPa}$, which is substantially higher than the tensile fracture strength.

\section{DISCUSSION}

Mo silicides, like other refractory-metal silicides, are very brittle at ambient temperatures. In this study, two metallurgical steps have been used to improve the fracture toughness of Mo silicide alloys. One step is to prepare multiphase Mo silicides containing ductile Mo particles, which are capable of deflecting crack growth in silicide phases. The amount of the Mo phase is controlled by 

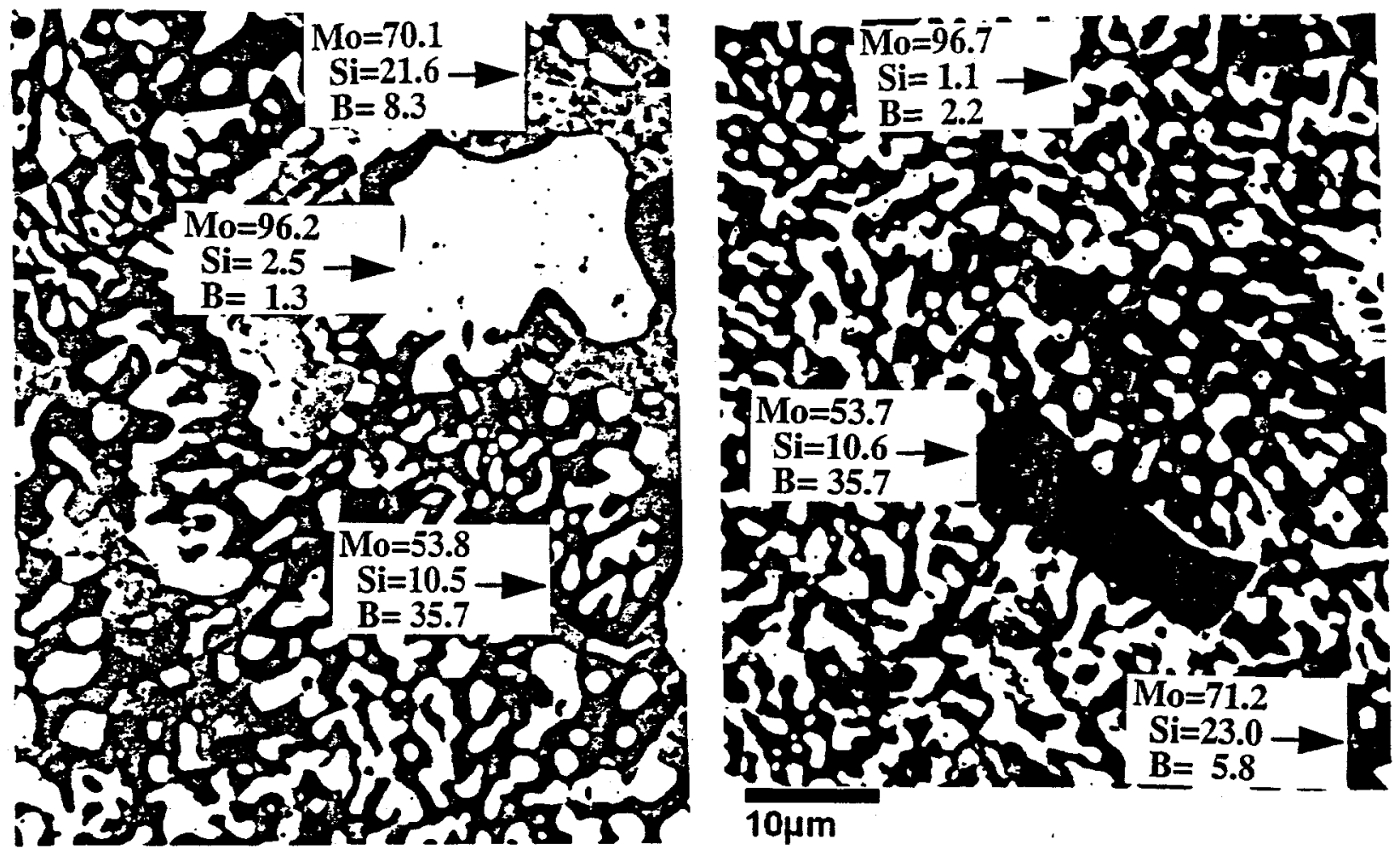

Fig. 4 Comparison of back-scattered images of M\&C MSB-18 (a) and MSB-21 (b)

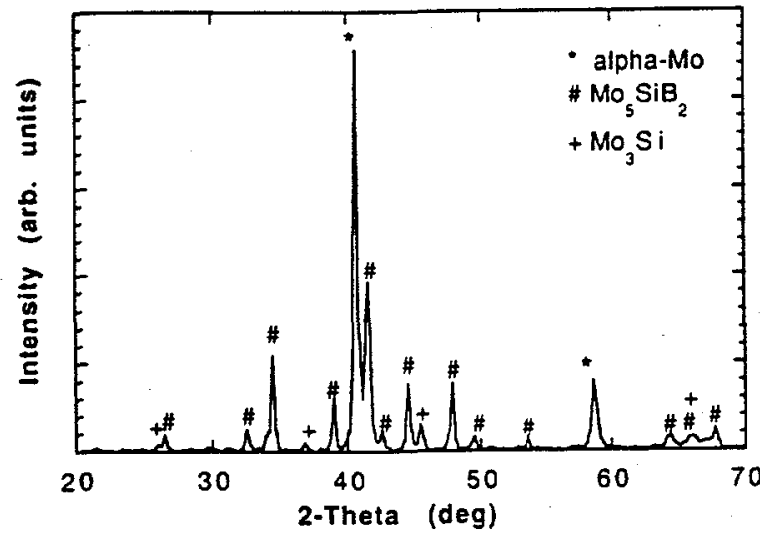

Fig. 5 Diffraction pattern of MSB-18

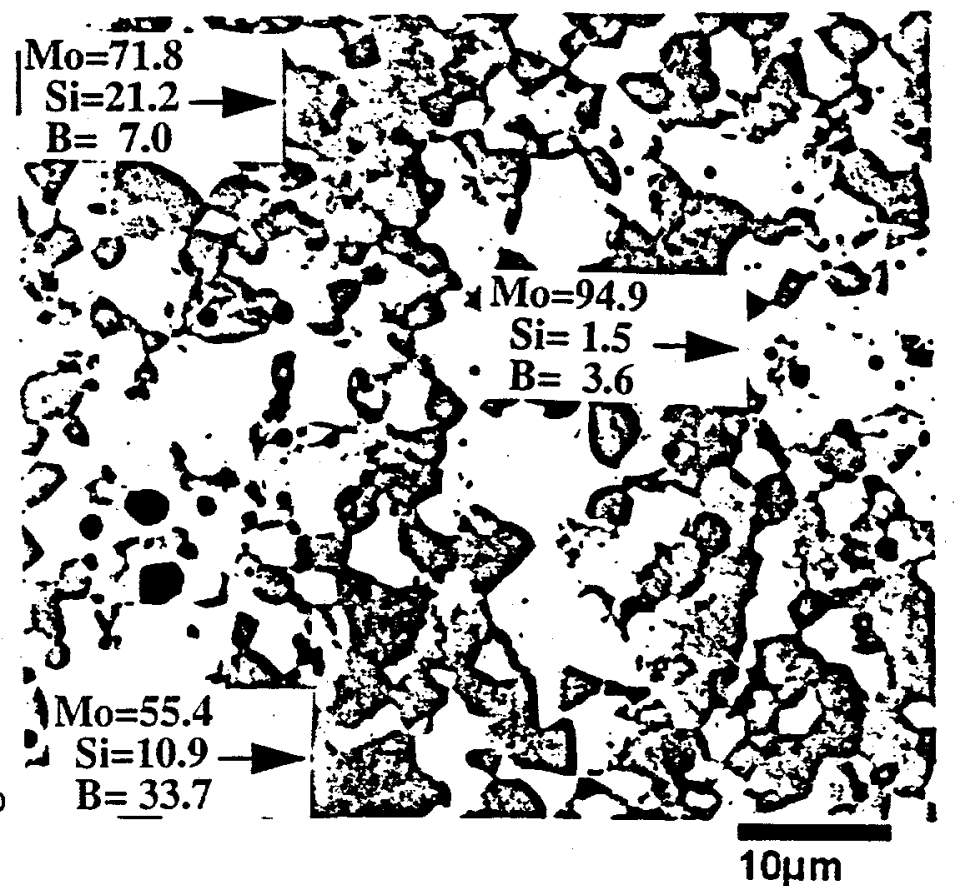

Fig. 6 Microstructure of PM MSB

the location of alloy compositions in the $\mathrm{T} 2-\mathrm{Mo}_{3} \mathrm{Si}-\mathrm{Mo}$ phase field, where the Mo-rich phase is thermodynamically stable with the two silicide phases. The second step is to refine multiphase 
Table 1: Room-temperature flexure properties of Mo silicide alloys

\begin{tabular}{|c|c|c|c|}
\hline Alloy & Heat Treatment & $\begin{array}{c}\text { Fracture } \\
\text { Toughness }\left(\mathrm{MPa} \mathrm{m}{ }^{1 / 2}\right)\end{array}$ & Flexure Strength $(\mathrm{MPa})$ \\
\hline \multirow{6}{*}{$\begin{array}{l}\mathrm{MSB}-18^{\mathrm{a}} \\
\mathrm{MSB}^{\mathrm{b}} \mathrm{b}^{\mathrm{b}} \\
\mathrm{MoSi}_{2} \\
\mathrm{MoSi}_{2} \\
\mathrm{MoSi}_{2}\end{array}$} & hot-pressed & 7.9 & \\
\hline & pressed+homogonized & 10.0 & 570 \\
\hline & hot-pressed & & 270 \\
\hline & hot-pressed & $\sim 2.6[9]$ & \\
\hline & hot-pressed & & $150[10]$ \\
\hline & hot-pressed & & $242[11]$ \\
\hline
\end{tabular}

microstructures designed to reduce the possibility of thermal-stress cracking caused by thermal expansion misfits among brittle silicide phases. An effective way to do so is to solidify multiphase alloys via eutectic reactions. The alloy compositions in this study were selected mainly for determining eutectic compositions in the three-phase field.

Nunes et al. [5] recently constructed the pseudo-binary Mo-T2 phase diagram as shown in Fig. 7. There exists a four-phase invariant point, where the $\mathrm{L}$ (liquid) and $\mathrm{Mo}_{2} \mathrm{~B}$ phases transfer into the Mo and T2 phase at $2100^{\circ} \mathrm{C}$. On the Mo-rich side, the primary phase is Mo-rich solid solution. and during cooling the $\mathrm{L}$ phase transfers into $\mathrm{Mo}$ and $\mathrm{T} 2$ phases through an eutectic reaction. On the T2-rich side, the primary phase is $\mathrm{T} 2$ and the $\mathrm{L}$ phase transfers into eutectic mixture of Mo and T2. Apparently, no simple eutectic reaction occurs in the pseudo binary system.

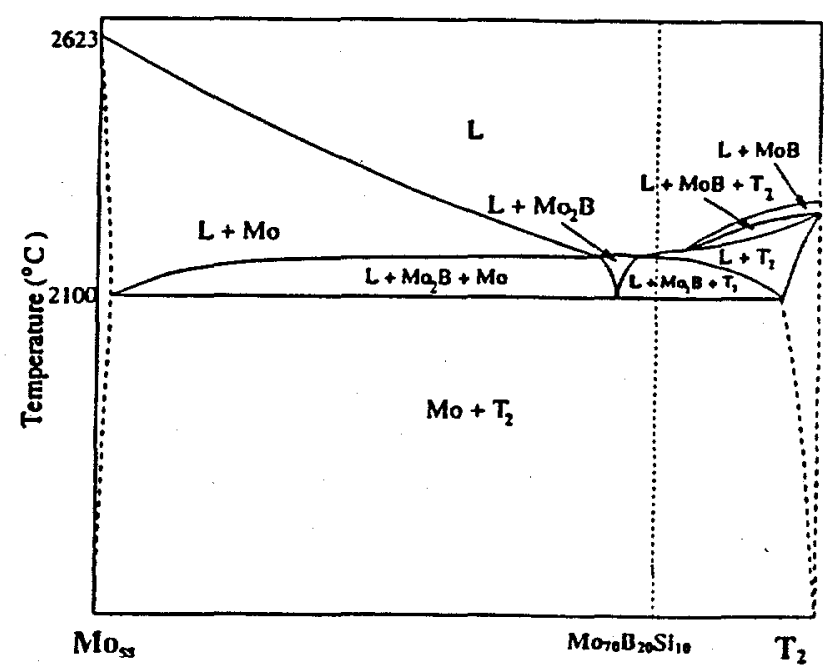

Fig. 7 The pseudo-binary Mo-T2 phase diagram [5]

In search for eutectic compositions, the alloy compositions used in the present study were selected near the invariant point but in the $\mathrm{T} 2-\mathrm{Mo}_{3} \mathrm{Si}-\mathrm{Mo}$ region. Microstructural studies indicate that the primary phase is Mo-rich solid solution in alloys containing $\leq(9.4 \mathrm{Si}+13.8 \mathrm{~B})$, with the solidification process as:

$$
\mathrm{L} \Rightarrow \mathrm{Mo}+\mathrm{L} \Rightarrow \mathrm{Mo}+\left\{\mathrm{Mo}+\mathrm{Mo}_{3}(\mathrm{Si} \cdot \mathrm{B})+\mathrm{T} 2\right\}
$$

The matrix contains fine mixed $\left\{\mathrm{Mo}+\mathrm{Mo}_{3}(\mathrm{Si}, \mathrm{B})+\mathrm{T} 2\right\}$ phases, which appear to be produced by an eutectic reaction. For alloys with $\geq(9.8 \mathrm{Si}+14.6 \mathrm{~B})$, the primary phase is $\mathrm{T} 2$ and the solidification process is: 


$$
\mathrm{L} \Rightarrow \mathrm{T} 2+\mathrm{L} \Rightarrow \mathrm{T} 2+\left\{\mathrm{Mo}+\mathrm{Mo}_{3}(\mathrm{Si}, \mathrm{B})+\mathrm{T} 2\right\}
$$

Thus, the eutectic composition is believed to be close to Mo-9.6Si-14.2B. Additional studies are certainly required to verify the eutectic composition.

The homogenization treatment for $150 \mathrm{~h}$ at $1400^{\circ} \mathrm{C}$ resulted in lowering the microhardness and increasing fracture toughness as shown in Table 1. It is important to point out that no microcracks were observed around indentations in the matrix silicide phases even though the hardness is $>1050$ DPH. On the other hand, microcracks are observed around indentation in the coarse primary T2 phase. Thus, refinement of microstructures by eutectic reactions reduces the crack tendency of brittle silicide phases. As indicated in Table 1, the multiphase MSB-18 containing ductile Mo-rich particles has a flexure strength distinctly higher than that of MSB-1 and $\mathrm{MoSi}_{2}$ alloys containing silicide phases without ductile Mo particles. In comparison with $\mathrm{MoSi}_{2}$ [9], the multiphase MSB18 is tougher than $\mathrm{MoSi}_{2}$ by a factor of 4 . Metallographic evidence indicates that Mo-rich particles are quite effective in deflecting microcracks in MSB-18 specimens. The tensile fracture strength of the MSB-18 specimens produced by PM and M\&C is almost the same, in spite of their difference in microstructure (see Fig $4 \mathrm{a}$ and 6). This comparison suggests that defects, such as microporosity, may play a key role in controlling the final fracture process. Future work will include the determination of tensile properties of multiphase silicide alloys after HIPing.

\section{ACKNOWLEDGMENT}

This research was sponsored by the Division of Materials Sciences, US Department of Energy under contract number DE-AC05-960R22464 with Lockheed Martin Energy Corporation. The authors would like to thank D. S. Easton, J. L. Wright and C. A. Carmichael for their technical asistance.

\section{REFERENCES}

1. A. J. Thom, M. K. Meyer, Y. Kim, and M. Akinc, in "Processing and Fabrication of advanced Materials III," V. A. Ravi et al., eds., TMS, p. 413 (1994).

2. M. K. Meyer, M. J. Kramer, and M. Akinc, Intermetallics, 4, 273 (1996).

3. M. K. Meyer, M. J. Kramer, and M. Akinc, Adv. Mater. 8, 85 (1996).

4. J. H. Perepezko, C. A. Nunes, S. -H. Yi, and D. J. Thoma, MRS Proc. Vol. 460, C. C. Koch et al., eds., pp. 3-14 (1997).

5. C. A. Nunes, R. Sakidja, and J. H. Perepezko, in "Structural Intermetallics 1997 " , M. V.

Nathal et al., eds., TMS, pp. $831-39$ (1997).

6. J. H. Schneibel. C. T. Liu, L. Heatherly, and M. J. Kramer, Scr. Mater. 38, 1169 (1998) and 39, 831 (1998).

7. H. Nowotny, E. Dimakopoulou, and H. Kudielka, Mh. Chem., 88, 180 (1957).

8. D. M. Berczik, United States Patent No. 5,595,616 (1997).

9. M. G. Hebsur and M. V. Nathal, in "Structural Intermetallics 1997", M. V. Nathal et al., eds., TMS, 949-58 (1997).

10. F. D. Gac and J. J. Petrovic, J. Am. Ceram. Soc. 68, C-200 (1985).

11. S. Chin, D. L. Anton, and A. F. Giamei, "Advanced MoSi, Compositions", Final Technical Report, AFSOR, R95-970281-4 (1996). 